\title{
Medical termination of pregnancy and subsequent adoption of contraception
}

\section{Ravish Haradanhalli Shankaraiah*, Rachana Rajashekhara Annadani, Veena Vijayashankar, Malatesh Undi}

Department of Community Medicine, Kempegowda Institute of Medical Sciences, Banashankari $2^{\text {nd }}$ Stage, Bangalore, Karnataka, India

Received: 17 June 2013

Accepted: 29 June 2013

\section{*Correspondence:}

Dr. Ravish Haradanhalli Shankaraiah

E-mail: drravishhs@ rediffmail.com

(C) 2013 Shankaraiah RH et al. This is an open-access article distributed under the terms of the Creative Commons Attribution Non-Commercial License, which permits unrestricted non-commercial use, distribution, and reproduction in any medium, provided the original work is properly cited.

\begin{abstract}
Background: The reasons for seeking MTP ranged from proximate causes such as desire to limit family size or space pregnancies, seeking abortion for medical reasons or availing it on medical advice to distal determinants such as poverty, violence and belief system. Therefore, the present study was undertaken to study the factors influencing MTPs \& the subsequent adoption of contraceptive methods following MTP.

Methods: The study subjects included women who underwent MTP at the hospital during the study period. The details regarding their socio demographic profile, previous obstetric history, reason for seeking abortion and acceptance of post abortal contraception were taken.

Results: 103 women who sought MTP during the study period were included in the study. Among the MTP seekers $22(21.4 \%)$ women had history of one or more abortions in the recent past. Most of the study subjects i.e., 41 (39.8\%) sought MTP for socio-economic reasons. The other conditions were eugenic reasons among 40 (38.9\%) and medical reasons $10(9.1 \%)$, only $12(11.6 \%)$ women sought MTP for contraceptive failure. Adoption of contraception following MTP was seen only among $52(50.5 \%)$.

Conclusions: Eligible couples have to be educated regarding the availability of different methods of contraceptives and their proper use to avoid pregnancy as long as they want. Similarly, all MTP seekers should be provided information and counseling for post-abortal contraceptive use and enable these women and their spouse to make an informed and voluntary choice and thus avoid the need of a repeat abortion.
\end{abstract}

Keywords: Medical termination of pregnancy, Reasons for MTP, Post abortal contraceptive usage

\section{INTRODUCTION}

Medical Termination of Pregnancy (MTP) represents an important aspect of women's reproductive health and right. Women's access to safe abortion services is essential to safeguard their health and is one of the important components of Reproductive and Child Health Programme. Even in countries where contraceptives are easily available and commonly used, the number of unintended pregnancies remains high. A large proportion of these unintended pregnancies end up in abortions.
MTP is the most controversial area of family planning, yet, it is often the most important method of fertility regulation by the community in the struggle to control family size. In reality contraception and induced abortions are complementary methods of fertility regulation. Many women consider abortion as a method of contraception. Though awareness of contraception is high, lack of availability of spacing methods, misinformation and apprehension about the different contraceptive options prevents widespread contraceptive use and abortion is used as an alternative to contraception. 
The MTP Act of India, 1971 has been a symbol of hope and a landmark in social and medical legislation, with far reaching positive benefits for the reproductive health of women. It is a protective foil for the healthcare system and its beneficiaries. The MTP act allows abortion for the conditions such as medical reasons which endangers the life of mother, birth of a child with abnormalities, socio-economic, humanitarian \& contraceptive failure. Since the enactment of the MTP act in India, there is a marked increase in the number of acceptors for abortions. The increase in abortion acceptors may be due to awareness about MTP act, changing attitude of women towards abortion, improvement in the availability of hospital facilities and declining social stigma attached to abortion.

The liberalization of MTP laws has resulted in a dramatic increase in the number of abortions over the years, but the data on attitude, behavior and practices related to abortion are not very conclusive and vary from place to place. This information is necessary for improving the abortion services and increasing the subsequent adoption of contraception. Despite the sizable literature on abortions, understanding of the nature and interaction of the different factors influencing the decision to terminate pregnancy remains limited. The reasons for seeking abortion reported in the various studies ranged from proximate causes such as a desire to limit family size or space pregnancies, seeking abortion for medical reasons or availing it on medical advice to distal determinants such as poverty, violence and belief system. Therefore, the present study was undertaken in a hospital, to study the factors influencing MTPs \& the subsequent adoption of contraceptive methods following MTP/ reasons for not adopting contraceptive methods.

\section{METHODS}

The study was conducted at the Department of Obstetrics \& Gynaecology, Kempegowda Institute of Medical Sciences Hospital \& Research Centre, Bangalore, India. The study subjects included women who underwent MTP at the hospital during the study period of one year (Jan. 2012 - Dec. 2012).

The details regarding the reason for seeking abortion and acceptance of post abortal contraception was taken among all the MTP seekers. A detailed information regarding socio demographic profile, parity, number of living children, age of previous child, duration of pregnancy, factors influencing MTP were collected through a pre designed and pre tested case record form and information regarding subsequent use of contraceptive methods used/ reasons for not adopting contraception were collected through house visits or by telephonic interview.

The data obtained was analyzed statistically including mean, percentage distribution and chi square test.

\section{RESULTS}

One hundred and three women who sought MTP in the hospital during the study period were included in the study. The socio - demographic profile of these women were as follows:

Majority of the MTP seekers were in the age group of 1825 years $(49.5 \%)$, followed by $25-35$ years $(39.8 \%)$ and $35-45$ years $(8.8 \%) .2(1.9 \%)$ of the study subjects were below 18 years of age. The mean age of women who underwent abortion was $25.2 \pm 4.7$ years. In the study population, most of them were studied up to intermediate $34(33.0 \%)$. According to socio economic status, majority of the MTP seekers $41(39.8 \%)$ belonged to class II, followed by class III $33(32.0 \%)$ and most of the MTP seekers were house makers 84 (83.4\%) (Table 1).

Table 1: Socio-demographic profile of MTP seekers $(\mathbf{n}=\mathbf{1 0 3})$.

\begin{tabular}{|c|c|c|c|}
\hline \multicolumn{2}{|c|}{ Characteristics } & Number & Percentage \\
\hline \multirow{4}{*}{$\begin{array}{l}\text { Age (in } \\
\text { years) }\end{array}$} & $<18$ & 2 & 1.9 \\
\hline & $18-25$ & 51 & 49.5 \\
\hline & $25-35$ & 41 & 39.8 \\
\hline & $35-45$ & 9 & 8.8 \\
\hline \multirow{6}{*}{$\begin{array}{l}\text { Level of } \\
\text { education }\end{array}$} & $\begin{array}{l}\text { Graduate/ Post } \\
\text { graduate }\end{array}$ & 22 & 21.4 \\
\hline & Intermediate & 34 & 33 \\
\hline & High school & 24 & 23.4 \\
\hline & Middle school & 14 & 13.5 \\
\hline & Primary school & 3 & 2.9 \\
\hline & Illiterate & 6 & 5.8 \\
\hline \multirow{4}{*}{$\begin{array}{l}\text { Socio - } \\
\text { economic } \\
\text { status* }\end{array}$} & 1 & 11 & 10.7 \\
\hline & 2 & 41 & 39.8 \\
\hline & 3 & 33 & 32 \\
\hline & 4 & 18 & 17.5 \\
\hline \multirow{2}{*}{ Occupation } & House wife & 84 & 83.4 \\
\hline & Working & 19 & 16.6 \\
\hline \multirow{2}{*}{$\begin{array}{l}\text { Marital } \\
\text { status }\end{array}$} & Married & 98 & 95.1 \\
\hline & Unmarried & 5 & 4.9 \\
\hline
\end{tabular}

*Modified Kuppuswamy classification

Among the MTP seekers $22(21.4 \%)$ women had history of one or more abortions in the recent past (Table 2). Similarly, $57(55.34 \%)$ women had one or more living children i.e., $34.9 \%$ of the women had one living child, 
$12.6 \%$ had 2 children and $8.7 \%$ of them had more than 2 children (Table 3). The age of previous child was found to be less than 1 year in $2.9 \%$ and less than 3 years among $29.1 \%$ of the women who sought MTP (Table 4).

Table 2: History of previous abortion/s $(n=103)$.

\begin{tabular}{|lll|}
\hline Previous abortion & Number & Percentage \\
\hline Yes & 22 & 21.4 \\
\hline No & 81 & 78.6 \\
\hline Total & 103 & 100.00 \\
\hline
\end{tabular}

Table 3: Distribution of women according to number of living children $(n=57)$.

\begin{tabular}{|lll|}
\hline Children & Number & Percentage \\
\hline 1 & 36 & 34.9 \\
\hline 2 & 12 & 12.6 \\
\hline$>2$ & 9 & 8.7 \\
\hline
\end{tabular}

Table 4: Distribution of women according to age of the previous child $(n=57)$.

\begin{tabular}{|lll|}
\hline Age & Number & Percentage \\
\hline$<1$ year & 3 & 2.9 \\
\hline 1-3 years & 30 & 29.1 \\
\hline 3-5 years & 8 & 7.8 \\
\hline$>5$ years & 16 & 15.6 \\
\hline
\end{tabular}

Most of the study subjects i.e., 41 (39.8\%) sought MTP for socio-economic reasons. The other conditions were eugenic reasons among $40(38.9 \%)$ and medical reasons $10(9.1 \%)$, whereas only $12(11.6 \%)$ women sought MTP for contraceptive failure (Table 5). Among them 6 women had failure of barrier methods i.e., 3 failures due to oral contraceptive pills, 2 failures of intrauterine devices and 1 failure of tubectomy.

Table 5: Distribution of women according to the conditions for MTP $(n=103)$.

\begin{tabular}{|lll|}
\hline Conditions & Number & Percentage \\
\hline Socio-economic & 41 & 39.8 \\
\hline Eugenic & 40 & 38.9 \\
\hline Contraceptive failure & 12 & 11.6 \\
\hline Medical & 10 & 9.7 \\
\hline Total & 103 & 100.00 \\
\hline
\end{tabular}

Adoption of contraception following MTP was seen only among $52(50.5 \%)$ subjects. Of these, 21 women adopted tubectomy who had 2 or more children, 12 women who had one child accepted Intra Uterine Device, 7 women adopted oral contraceptives and 1 woman with one child adopted injectable hormone. In addition, 11 husbands of women with one child adopted barrier method (Table 6).

Table 6: Contraceptive methods used following $\operatorname{MTP}(n=52)$.

\begin{tabular}{|lll|}
\hline Method & Number & Percentage \\
\hline Barrier method & 11 & 21.2 \\
\hline OCP & 7 & 13.5 \\
\hline $\mathrm{Cu} \mathrm{T}$ & 12 & 23.1 \\
\hline Injectables & 1 & 1.9 \\
\hline Tubectomy & 21 & 40.3 \\
\hline Total & 52 & 100.00 \\
\hline
\end{tabular}

The acceptance of concurrent contraception showed significant positive association with increasing age $(\mathrm{P}=$ $0.0006)$ and parity $(\mathrm{P}<0.0001)$ (Table $7 \& 8)$.

Table 7: Association between acceptance of concurrent contraception and age.

\begin{tabular}{|c|c|c|c|c|}
\hline \multirow[b]{2}{*}{ Age } & \multicolumn{2}{|c|}{ Contraception } & \multirow{2}{*}{$\begin{array}{l}\text { Chi } \\
\text { square } \\
\text { value }\end{array}$} & \multirow[b]{2}{*}{ P value } \\
\hline & Adopted & $\begin{array}{l}\text { Not } \\
\text { adopted }\end{array}$ & & \\
\hline$<30$ & 27 & 43 & \multirow{2}{*}{12.41} & \multirow{2}{*}{0.00043} \\
\hline$>30$ & 25 & 8 & & \\
\hline
\end{tabular}

Table 8: Association between acceptance of concurrent contraception and parity.

\begin{tabular}{|lllll|} 
& \multicolumn{2}{l}{ Contraception } & Chi \\
Parity & Adopted & $\begin{array}{l}\text { Not } \\
\text { adopted }\end{array}$ & $\begin{array}{l}\text { Square } \\
\text { value }\end{array}$ & P value \\
\cline { 2 - 3 } & 32 & 50 & 21.13 & 0.0000042 \\
\hline$<2$ & 20 & 1 & & \\
\hline$>2$ & & & & \\
\hline
\end{tabular}

The main reason given for not accepting any postabortion contraception was "husband objected" among 16 $(32 \%)$. Other reasons included "do not want" in $9(18 \%)$, "Family Planning method fails" among 8 (16\%), while 17 (34\%) did not respond (Table 9). 
Table 9: Reasons for not accepting contraceptive methods $(\mathbf{n}=\mathbf{5 1})$.

\begin{tabular}{|lll|}
\hline Reasons & Number & Percentage \\
\hline Husband objected & 16 & 32 \\
\hline Do not want & 9 & 18 \\
\hline $\begin{array}{l}\text { Family Planning } \\
\text { method also fails }\end{array}$ & 8 & 16 \\
\hline Did not respond & 17 & 34 \\
\hline Total & 51 & 100.00 \\
\hline
\end{tabular}

\section{CONCLUSION}

Safe and legal abortion i.e., MTP is considered a key intervention for improving women's health and quality of life. There is a gradual increase in MTP acceptance over the years due to liberalization \&awareness about MTP act, changing attitude of women towards abortion, improvement in the availability of hospital facilities and declining social stigma attached to abortion. Reproductive preferences \& behavior among women vary widely with demographic, socio economic and other factors. The present study focused mainly on the reasons for MTP and adoption of contraception following MTP.

Majority of the MTP seekers were in the age group of 1834 years. Similarly, Chhabra et al in their study showed that more than 80 percent of women who obtain MTP were in the age group of 20-34. ${ }^{1}$ This shows that younger women seeks MTPs more frequently rather than the older women, which may be attributed to lack of motivation and decision making among these younger women for accepting contraceptive measures either to postpone pregnancy or to complete the family.

The present study showed that 57 (56.2\%) MTP seekers had one or more living children, among them $9(8.7 \%)$ had 2 or more living children and completed their family. Similarly 33 (32\%) of them had child less than 3 years of age which is the ideal spacing period. Dhillon BS et al, in their study also showed that 47.3 per cent of the women seeking MTP had parity of three or more. ${ }^{2}$ This reveals that there is lack of proper knowledge and motivation among these women for accepting contraception, which has to be done by the health care personnel.

The present showed that $22(21.4 \%)$ women who sought MTP had history of one or more abortions in the recent past. Similarly, a study done by Shipra Guptha et al, showed that $12.5 \%$ of women had previous history of abortion/s. ${ }^{3}$ Another study done by Ganguly et.al., also showed that $5.7 \%$ of women had previous history of abortion/s. ${ }^{4}$ This shows that many women consider abortion as a method of contraception. The health care provider should insist for post abortion contraception and provide information and counseling to enable the women and spouse to make an informed and voluntary choice and thus avoid the need of a repeat abortion. Contraceptive services should also include emergency contraceptives to prevent unwanted pregnancy.

Many women consider medical termination of pregnancy as a method of contraception. This is supported by the fact that, in our study the most common factor responsible for seeking abortion was unwanted pregnancy and that they did not want children due to socio economic reasons in $39.8 \%$ percent. Only $11.6 \%$ percent women sought MTP due to failure of contraception. Similarly, Khokhar et al, in their study at urban slums of Delhi noted that the most common reasons for the abortion stated by the women undergoing MTP were unplanned pregnancy, inadequate income\& completedfamily. ${ }^{5}$ Similarly, Dhillon et. al., in their study found that the most common reason given for terminating the pregnancy was "did not want any more children" in $42 \%{ }^{2}$ This shows that, the eligible couples has to be educated regarding the availability of different methods of contraceptives and their proper use will definitely avoids pregnancy as long as they want.

The present study showed that the adoption of Postabortion contraception was only among 52 (50.4\%). Similarly, a study done by Dhillon BS et al showed that the acceptance of post abortal contraception was only among $48.9 \%$ of the women. Of these, $37.2 \%$ accepted an Intra Uterine Device/oral contraceptive (IUD/OC) and $49.1 \%$ a permanent method. ${ }^{2}$ This shows that, unmet needs of contraception is still existing as more than half of MTP seekers in our study adopted contraceptive measures after MTP. Though awareness of contraception is high, lack of availability of spacing methods, misinformation and apprehension about the different contraceptive options prevents widespread contraceptive use and abortion is used as an alternative to contraception. It was observed that, although post abortion clients clearly wanted to avoid another unwanted pregnancy, they generally failed to receive family planning information and services. Abortion providers did not view contraceptive provision as their subsequent responsibility \& services for MTP and family planning often will not be available on the same day or in the same location. ${ }^{6}$ This indicate the failure on the part of health care providers to counsel these women on need for temporary or permanent methods of contraception.

In conclusion, women access MTP for various reasons throughout their reproductive years. The present study showed that the important factor responsible for seeking MTP was unwanted pregnancy due to socio economic reasons in $39.8 \%$. This can be avoided by educating eligible couples regarding the availability of different methods of contraceptives and their proper use to avoid pregnancy as long as they want. Adoption of post abortion contraception is important for avoiding unwanted pregnancies, still the acceptance of post abortal contraception is found to be only by $50.5 \%$ of the 
women. Therefore, the health care providers should provide information and counseling for post-abortal contraceptive use and enable these women and their spouse to make an informed and voluntary choice and thus avoid the need of a repeat abortion.

\section{Funding: None}

Conflict of interest: None declared

Ethical approval: Not required

\section{REFERENCES}

1. Chhabra, Rami and Sheel C. Nuna. Abortion in India: An Overview. New Delhi 1994: Veerendra printers.

2. Dhillon BS, Chandhiok N, Kambo I, Saxena NC. Induced abortion and concurrent adoption of contraception in the rural areas of India (An ICMR task force study). Indian Journal of Medical Sciences. 2004;58(11):478-84.
3. Shipra Gupta, Viral Dave, Kishor Sochaliya, Sudha Yadav. A Study on socio-demographic and obstetric profile of MTP seekers at Guru Govind Singh Hospital, Jamnagar. Health Line. 2012; 3 (1): 5054.

4. Ganguly G; Biswas A; Sharma GD. Profile of women undergoing medical termination of pregnancy in hospital. Journal of the Indian Medical Association. 1993; 91(11):286-7.

5. Khokhar A., Gulati N. Profile of Induced Abortions in Women from an Urban Slum of Delhi. Indian Journal of Community Medicine. 2000; 25(4): 1012.

6. Chandhick N, Kambo I, Dhillon BS, Saxena NC. Contraceptive knowledge, practices and utilization of services in the rural areas of India (An ICMR task force study). Ind J Med Sci 2003; 57:303-10.

DOI: $10.5455 / 2320-1770$. ijrog 20130921

Cite this article as: Shankaraiah $\mathrm{RH}$, Annadani RR, Vijayashankar V, Undi M. Medical termination of pregnancy and subsequent adoption of contraception. Int J Reprod Contracept Obstet Gynecol 2013;2:367-71. 